\title{
"Formação profissional para a prevenção da infecção comunitária na estratégia de saúde da família"
}

\section{"professional training for community infection prevention in the family health strategy family health strategy"}

DOI: $10.46814 / \operatorname{lajdv3n4-027}$

Recebimento dos originais: 01/05/2021

Aceitação para publicação: 31/06/2021

\section{Guilherme Holanda Bezerra}

Mestrando no programa de pós-graduação de clínica médica da Universidade Estadual de Campinas

Universidade Federal do Piauí - Campus Senador Helvídio Nunes de Barros.

Rua Cícero Eduardo,S/N. Bairro: Junco Picos-PI

E-mail: guilherme.h.b@hotmail.com

\section{Nelita D'Iolanda Costa Moura}

Graduanda no curso de Bacharelado em Medicina da Universidade Federal do Piauí - Campus

Senador Helvídio Nunes de Barros

Universidade Federal do Piauí - Campus Senador Helvídio Nunes de Barros

Rua Cícero Eduardo,S/N. Bairro: Junco Picos-PI

E-mail: nelitadi@gmail.com

\section{Nathália Cunha Lima D'Assunção}

Graduanda do curso de bacharelado em Medicina da Universidade Federal do Piauí campus Senador Helvídio Nunes de Barros.

Universidade Federal do Piauí - Campus Senador Helvídio Nunes de Barros

Rua Cícero Eduardo,S/N. Bairro: Junco Picos-PI

E-mail: nathaliadassuncao@gmail.com

\section{Maria Dara Lopes de Moraes}

Graduanda do curso de bacharelado em Medicina da Universidade Federal do Piauí campus Senador

Helvídio Nunes de Barros.Universidade Federal do Piauí - Campus Senador Helvídio Nunes de Barros

Rua Cícero Eduardo,S/N. Bairro: Junco Picos-PI

E-mail: mariadaralopes@hotmail.com

\section{Pedro Gabriel Almeida Silva Sousa}

Graduando do curso de bacharelado em Medicina da Universidade Federal do Piauí campus Senador Helvídio Nunes de Barros.

Universidade Federal do Piauí - Campus Senador Helvídio Nunes de Barros.

Rua Cícero Eduardo,S/N. Bairro: Junco Picos-PI

E-mail: pedroalmeida@ufpi.edu.br

\section{Beatriz Feitosa Leite de Lima}

Graduanda do curso de bacharelado em Medicina da Universidade Federal do Piauí campus Senador Helvídio Nunes de Barros.Universidade Federal do Piauí - Campus Senador Helvídio Nunes de 
E-mail: beatrizfeitosa_lima@hotmail.com

Argemiro Mendes Feitosa Neto

Graduando do curso de bacharelado em Medicina da Universidade Federal do Piauí campus Senador Helvídio Nunes de Barros.Universidade Federal do Piauí - Campus Senador Helvídio Nunes de Barros

Rua Cícero Eduardo,S/N. Bairro: Junco Picos-PI

E-mail: argemiro@ufpi.edu.br

\title{
Maria Eliete Batista Moura
}

Pós-Doutorado pela Universidade Aberta de Lisboa - Portugal

Universidade Federal do Piauí, Centro de Ciências da Saúde.Av. Petrônio Portela Ininga 64000000 -

Teresina, PI - Brasil

E-mail: liamoura@ufpi.edu.br

\section{RESUMO}

A Estratégia de Saúde da Família mantem-se próxima à comunidade, valorizado seus contextos socioculturais e econômicos e, assim, agir através da prevenção, promoção e vigilância em saúde. Nesse viés, sendo as doenças infecciosas comunitárias uma relevante problemática para a saúde pública que dispõe-se, como principal ferramenta de combate, a prevenção da contaminação, o profissional da saúde, como cuidador e educador, tem um papel essencial nesse caráter preventivo do sistema. Desse modo, é fundamental a análise da formação desses profissionais, sejam eles médicos, enfermeiros ou odontólogos. Por meio do estudo descritivo de um questionário aplicado para estudantes de um centro universitário privado, caracterizou-se a avaliação, de acordo com os mesmos, do ensino sobre o controle de infecções comunitárias na ESF e também o conhecimento sobre formas de infecção e prevenção da infecção comunitária. Observou-se que, mesmo o assunto sendo abordado em algumas disciplinas, faz-se necessário maior aprofundamento, principalmente visando o preenchimento da lacuna entre teórico e prático na clínica.

\begin{abstract}
The Family Health Strategy stays close to the community, valuing its sociocultural and economic contexts and, thus, acting through prevention, promotion, and health surveillance. In this perspective, as community infectious diseases are a relevant problem for public health that has, as its main combat tool, the prevention of contamination, the health professional, as a caregiver and educator, has an essential role in this preventive character of the system. Thus, it is essential to analyze the training of these professionals, whether they are doctors, nurses, or dentists. Through a descriptive study of a questionnaire applied to students from a private university center, we characterized the evaluation, according to them, of the teaching about the control of community infections in the ESF and also the knowledge about forms of infection and prevention of community infection. It was observed that, even though the subject is addressed in some disciplines, more in-depth study is needed, mainly aiming to fill the gap between theoretical and practical in clinical practice.
\end{abstract}

\section{INTRODUÇÃO}

A Política Nacional de Atenção Básica (PNAB) define a Atenção Básica como “o conjunto de ações de saúde individuais, familiares e coletivas que envolvem promoção, prevenção, proteção, diagnóstico, tratamento, reabilitação, redução de danos, cuidados paliativos e vigilância em saúde, 
desenvolvida por meio de práticas de cuidado integrado e gestão qualificada, realizada com equipe multiprofissional e dirigida à população em território definido, sobre as quais as equipes assumem responsabilidade sanitária"1. Essa é considerada o primeiro contato do paciente ao sistema de saúde, possuindo a função de filtro, fundamental para o funcionamento do sistema ${ }^{2}$.

A interação entre o profissional de saúde e os usuários dos serviços de saúde é de suma importância para a realização das práticas de saúde, devido a realização de orientações sobre rotinas e cuidados necessários para a prevenção de enfermidades e promoção de saúde, devendo ser feita de maneira clara e didática, garantindo um entendimento pleno sobre as informações transmitidas pelo profissional, caracterizando assim a educação em saúde ${ }^{3}$.

Segundo o Ministério da Saúde, a educação em saúde é definida como um processo de construção de conhecimentos em saúde por parte da população, objetivando assim sua autonomia tanto no ato do cuidado individual como no coletivo e em debates com profissionais de saúde e gestores, visando uma maior cobertura de acordo com suas necessedades e demandas ${ }^{4}$.

Assim, o desenvolvimento de uma doença infecciosa depende da interação entre o potencial de ataque dos microrganismos e os mecanismos de defesa do organismo, fatores passiveis à processos de prevenção. A infecção pode ser caracterizada como a presença de um organismo, e sua proliferação, em qualquer parte do corpo, desencadeando uma resposta imunológica do hospedeiro 5 .

Desta forma, visando uma prevenção mais efetiva contra tais infecções, faz-se necessária a educação em saúde, que baseia-se em três pilares básicos, sendo eles: o profissional de saúde que realiza as orientações para prevenção e a promoção de saúde, os gestores que apoiam tais condutas preventivas e por fim a população, alvo final da construção do conhecimento em saúde ${ }^{6}$.

\section{OBJETIVOS}

Avaliar a formação dos profissionais para o controle de infecção na estratégia de saúde da família.

Avaliar a formação dos profissionais médicos, enfermeiros e odontólogos para o controle de infecção comunitária na estratégia de saúde da família e comparar entre os mesmos.

Identificar na matriz curricular dos cursos, as disciplinas sobre prevenção e controle da infecção da comunidade.

Analisar a interdisciplinaridade entre as matérias em relação ao controle de infecção comunitária. 


\section{METODOLOGIA}

Trata-se de um estudo descritivo, sendo aplicado um questionário aberto de avaliação, que foi administrado a estudantes de um centro universitário privado. Os dados serão coletados mediante o consentimento expresso da instituição e da população em estudo, após aprovação pelo Comitê de Ética em Pesquisa da UNINOVAFAPI com o número de CAAE 14424913.0.0000.5210. Destaca-se que foram obedecidos todos os aspectos da resolução 196/86 de 2012, que tem os parâmetros éticos que envolvam seres humanos. Assim, a população será representada sem ônus, ao participar como sujeito da pesquisa. Neste sentido, a coleta dos dados ocorreu em abril de 2013 atéagosto de 2013.A pesquisa foi realizada com os acadêmicos de medicina, odontologia e enfermagem de uma instituição privada que foi escolhida devido ao maior acesso à amostra do estudo. Foram excluídos alunos da pós-graduação e aqueles dos últimos períodos dos cursos por estarem em estágios obrigatórios e, portanto, com menor presença na instituição de ensino já mencionada. A amostra teve os acadêmicos de medicina com 22 estudantes, 27 de odontologia e 17 de enfermagem do ano de 2013.

A coleta de dados foi no ano de 2013 através do preenchimento por cada acadêmico de um questionário aberto. Os dados os dados foram analisados pelo IRAMUTQ que permite a análise lexical por meio da Classificação Hierárquica Descendente (CHD), que recorre a co-ocorrências das palavras no enunciado que constituem o material discursivo. O software organiza as informações consideradas mais relevantes, e que possui como referência em sua base metodológica a abordagem conceitual lógica e dos mundos lexicais ${ }^{7}$.O IRAMUTQ é um software que analisa o material a partir das grandes Unidades de ContextoIniciais (UCIs), que podem ser entrevistas de diferentes sujeitos reunidos no corpus, respostas e perguntas específicas, normalmente abertas, de questionários e texto de jornais e revistas. O texto completo é formatado e dividido em segmentos menores denominados de Unidades de Contexto Elementares (UCEs) que correspondem ao material discursivo ou escrito referente à formação das classes ou categorias ${ }^{8}$.

\section{DISCUSSÃO}

A caracterização social e demográfica dos acadêmicos por curso está catalogada a seguir.

QUADRO 1: Caracterização social e demográfica de acadêmicos de medicina do Centro Universitário UNINOVAFAPI. Teresina- PI

\begin{tabular}{|l|l|l|l|}
\hline VARIÁVEL & & $\mathbf{N}^{\mathbf{0}}$ & $\mathbf{\%}$ \\
\hline GÊNERO & 1 & 09 & 41,0 \\
\cline { 2 - 5 } & 2 & $\mathbf{1 3}$ & $\mathbf{5 9 , 0}$ \\
\hline \multirow{2}{*}{ IDADE (anos) } & 1 & 20 & 91,0 \\
\cline { 2 - 5 } & 2 & $\mathbf{0 1}$ & $\mathbf{4 , 5}$ \\
\hline
\end{tabular}




\begin{tabular}{|l|l|l|l|}
\hline & 3 & 01 & 4,5 \\
\hline
\end{tabular}

Fonte: Pesquisa direta. 2013.

QUADRO 2: Caracterização social e demográfica de acadêmicos de enfermagem do Centro Universitário UNINOVAFAPI. Teresina- PI

\begin{tabular}{|l|c|c|c|}
\hline VARIÁVEL & & $\mathbf{N}^{\mathbf{0}}$ & $\mathbf{\%}$ \\
\hline \multirow{2}{*}{ GÊNERO } & 1 & 07 & 41,0 \\
\cline { 2 - 5 } & 2 & $\mathbf{1 0}$ & $\mathbf{5 9 , 0}$ \\
\hline \multirow{2}{*}{ IDADE (anos) } & 1 & 12 & 71,0 \\
\cline { 2 - 5 } & 2 & $\mathbf{0 4}$ & $\mathbf{2 3 , 0}$ \\
\cline { 2 - 5 } & 3 & 01 & 6,0 \\
\hline
\end{tabular}

Fonte: Pesquisa direta. 2013

QUADRO 3: Caracterização social e demográfica de acadêmicos de odontologia do Centro Universitário UNINOVAFAPI. Teresina- PI.

\begin{tabular}{|l|l|l|c|}
\hline VARIÁVEL & & $\mathbf{N}^{\mathbf{0}}$ & \% \\
\hline \multirow{2}{*}{ GÊNERO } & 1 & 04 & 18,0 \\
\cline { 2 - 5 } & 2 & $\mathbf{1 8}$ & $\mathbf{8 2 , 0}$ \\
\hline \multirow{2}{*}{ IDADE (anos) } & 1 & 22 & 100,0 \\
\cline { 2 - 5 } & 2 & - & - \\
\cline { 2 - 5 } & 3 & - & - \\
\hline
\end{tabular}

Fonte: Pesquisa direta. 2013.

Após o processamento do corpus textual, houve a divisão dos segmentos de texto em seis classes semânticas, a saber:

1 Avaliação do curso pelos estudantes sobre o controle de infecção comunitária na ESF(13\%)

2 Tipos de infecções comunitárias adquiridas na ESF (17,6\%)

3 Interdisciplinaridade da grade curricular que abordam sobre o controle de infecção comunitária na $\operatorname{ESF}(20.3 \%)$

4 Formas de prevenção da infecção comunitária na estratégia de saúde da família (13,5\%)

5 Conceito de infecção comunitária $(17,6 \%)$.

6 Formas de contaminação de infecções comunitárias (13,5 \%) 
TABELA 1: Dendograma das classes

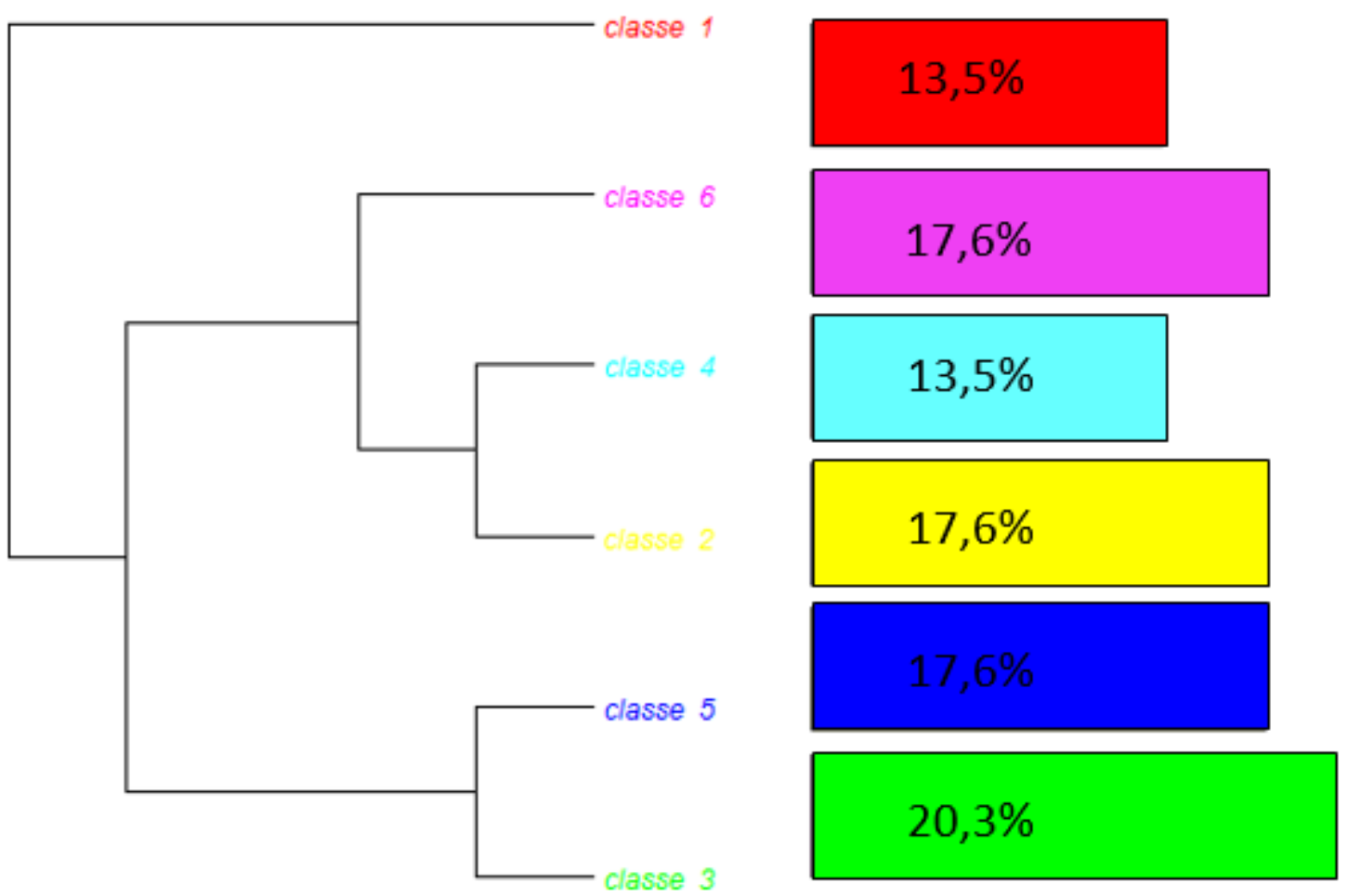

Os alunos entrevistados eram predominantemente do gênero feminino e com idade 20 a 25 anos, nos três cursos pesquisados.

A análise e interpretação das classes formadas estão a seguir:

Classe 1 - Avaliação do curso pelos estudantes sobre o controle de infecção comunitária na ESF.

A classe 1, com 10 segmentos de texto, representou $13,5 \%$ corpus. Os vocábulos (epidemiologia, processo, parasitologia, enfermagem, saúde, formação) apareceram com maior frequência e predominaram alunos do gênero feminino, com idade 20 a 25 anos e cursando enfermagem. Em suas falas, os estudantes demonstraram que apesar do assunto ser abordado em algumas disciplinas, se faz necessário maior aprofundamento durante o decorrer do curso.

\footnotetext{
"Estou no momento aprofundando meus conhecimentos sobre o tema, mas avalio como boa a minha formação sobre o tema"

"Vejo minha formação como excelente"

"Mediana mais acredito que no decorrer do curso melhore meus conhecimentos com relação as infecções, pois precisa ser melhorada a saúde coletiva"
}

Diante disso, é visto que os padrões acadêmicos, por sua vez, valorizam predominantemente o conhecimento científico disciplinar em detrimento do profissional. As prioridades de investigação não correspondem necessariamente às demandas trazidas do exercício profissional, afastando docentes envolvidos na pesquisa científica e os profissionais clínicos, sendo necessárias melhorias na forma de 
ensino para ensinar os estudantes a tomar decisões sob condições de incerteza, a lidar com a ambiguidade, expondo a fratura entre o mundo real e as práticas academicamente estruturadas 9 .

Classe 2 - Tipos de infecções comunitárias adquiridas na ESF

A classe 2, diretamente relacionada à classe 4, apresenta 13 segmentos de texto, ou seja, 17,6\% do corpus. Agrupou os vocábulos (gripe, verminose, varicela, meningite, AIDS, diarreia), com maior frequência de acadêmicos de enfermagem, gênero feminino e idade entre 30 a 35 anos. Os estudantes citaram as infecções comunitárias comumente apresentadas pelos usuários atendidos na Estratégia Saúde da Família que eles conheciam.

\footnotetext{
"verminose, síndromes gripais, catapora, varicela, diarreia, hanseníase, tuberculose e meningite"

“diversas patologias como DSTS, AIDS, herpes, sífilis, gripe, até infecção simples que possa atingir um grupo de pessoas como hepatite"

Em relação aos tipos de infecções comunitárias encontra-se:
}

Infecções Respiratórias

As doenças respiratórias, de acordo com a OMS, podem ser definidas como infecções que ocorrem no trato respiratório, tanto superior quanto inferior, nas quais há a obstrução da passagem do ar, tanto a nível basal quanto a nível bronquiolar e pulmonar ${ }^{10}$.

As Infecções Respiratórias Agudas (IRAs) estão entre as doenças infecçiosas de maior índice de morbimortalidade no mundo, afetando os mais jovens e os mais idosos, sendo essas divididas em Infecções das vias aéreas superiores (IVAS) que correspondem todas as infecções do trato respiratório acima da laringe, causadas principalmente pelos vírus Influenza A, Rhinovírus, Coronavírus e vírus Sincicial respiratório, e Infecções das vias aéreas inferiores (IVRI), que se inicia na porção intratorácica da traqueia, envolvendo seus dois terços inferiores, e podem desencadear quadros mais graves por serem causados principalmente por bactérias como Neisseria meningitidis, Streptococcus hemolyticos e Streptococcus pneumoniae e apresentam manifestações de gripe, bronquiolites, bronquites e pneumonias $^{10}$.

\section{Infecções Urinárias}

A infecção do trato urinário (ITU) é a segunda infecção mais recorrente na pediatria, estando atrás somente da respiratória e inicia-se quando bactérias do sistema digestivo alcançam o períneo e a porção distal da uretra e é estabelecida quando os microrganismos ascendem nos tecidos urinários, colonizando-os e desencadeando uma resposta inflamatória ${ }^{11}$.

A E. coli uropatogênica apresenta-se como principal fator de virulência, sendo responsável por cerca de $80 \%$ de todos os episódios de infecção, seguida por Staphylococcussaprophyticus, Klebsiellapneumoniae e Proteusmirabilis que promovem a ligação ao epitélio da uretra e da bexiga, 
acerretando Cistite Aguda, que apresenta como sintomas clássicos a disúria, aumento da frequência urinária, urgência miccional, dor suprapúbica e hematúria ${ }^{12}$. Já quando atingem o trato urinário superior, a patologia é denominada de Pielonefrite Aguda que pode ser definida como infecção que acomete a pelve e o córtex renal, podendo levar a insuficiência renal crônica e apresenta sintomas mais proeminentes $^{13}$.

Além da classificação quanto a anatomia, a ITU pode ser classificada quanto ao tempo de e evolução da doença, em que são divididas em agudas e crônicas ${ }^{13}$. Além disso, podem ser classificadas como complicada e não complicada. Aquela ocorre em mulheres jovens, não grávidas e na ausência de anomalias estruturais ou funcionais do trato urinário. Já as ITUs complicadas são aquelas que possuem fatores como diabetes, gravidez, falência renal, obstrução do trato urinário, presença de sonda vesical de demora, procedimento ou instrumentação cirúrgica recente no trato urinário, disfunções anatômicas ou funcionais, imunossupressão, transplante renal e história de ITU na infância ${ }^{12}$.

\section{Infecções Cutâneas}

As infecções bacterianas da pele são muito prevalentes na prática clínica e tem grande variabilidade de apresentações, etiologias e gravidades, sendo caracterizadas habitualmente pela presença de sinais de inflamação, associados ou não a manifestações como febre, ulceração, exulceração ou bolhas. A maioria dos casos de infecção cutânea bacteriana é causada por estreptococos beta-hemolíticos ou por Staphylococcus aureus ${ }^{14}$.

A espécie S. aureus pertence ao gênero Staphylococcus, família Staphylococcaceae e trata-se de bactérias esféricas, anaeróbias facultativas, gram positivas, e de coloração amarelada devido à produção de carotenoides e seres humanos são reservatórios naturais para S. aureus e a colonização assintomática é muito mais comum do que a infecção. Em relação a essa colonização, três perfis principais: o indivíduo não colonizado, que nunca ou raramente está colonizado por S. aureus, o indivíduo carreador persistente, que se encontra colonizado com os mesmos clones e possui alta carga bacteriana, e por fim, o carreador intermitente, que carreia diferentes clones em momentos distintos, sendo uma de suas principais características a grande capacidade adaptativa e de adquirir resistência, como ocorre com o S. aureus resistente à meticilina (MRSA), encontrados principalmente em crianças na comunidade ${ }^{15}$.

Classe 3 - Interdisciplinaridade da grade curricular que abordam sobre o controle de infecção comunitária na ESF

A classe 3, diretamente associada à classe 5, apresenta 15 segmentos de texto, 20,3\% do corpus. Reuniu os vocábulos (infectocontagiosas, doença, saneamento, hospitalar, pneumologia, orientar), com maioria de alunos do curso de medicina, Gênero masculino e idade entre 20 a 25 anos. No seu discurso 
os acadêmicos citaram quais disciplinas tinham abordado o assunto infecção comunitária no decorrer do curso.

\begin{abstract}
"Microbiologia, propedêutica médica, doenças infectocontagiosas, infecção hospitalar e infectologia" "Doenças infectocontagiosas, pneumologia, saúde da família e epidemiologia" "doenças infectocontagiosas, infecção hospitalar, TPE e síntese"
\end{abstract}

Classe 4 - Formas de prevenção da infecção comunitária na estratégia de saúde da família

Essa classe é diretamente relacionada à classe 2, apresenta 10 segmentos de texto, que correspondem a 13,5\% do corpus. Juntou os vocábulos (bucal, palestra, imunologia, cuidado, prevenir, carente, higiene), com a maioria de estudantes do curso de odontologia, gênero masculino e idade entre 20 a 25 anos. Os alunos entrevistados discorreram sobre as formas de prevenção da infecção comunitária que eles aprenderam e, até mesmo, já utilizaram na prática.

\footnotetext{
"palestras que possam informar as pessoas como se prevenir correta higiene até as distribuição de medicamentos para a população"

"a importância da higiene bucal minimizando essas infecções moderada já fiz algumas visitas em comunidades fazendo palestras mostrando o modo certo de escovação"

"Promover higiene ter cuidados alimentares para melhorar a resistência do organismo fazer promoção e prevenção de saúde"
}

Nesse contexto, as principais medidas de prevenção da infecção comunitária a serem desenvolvidas na estratégia de saúde da família envolvem ações educativas que trabalhem a forma mais adequada de se higienizar as mãos e técnicas de assepsia ${ }^{16}$. Os protocolos de higienização das mãos são estabelecidos pela Agência Nacional de Vigilância Sanitária e possuem o objetivo de remover os microrganismos que colonizam as camadas superficiais da pele, também retirando oleosidade, suor e células mortas. Essas medidas devem ser aplicadas principalmente em situações de contato com fluidos corporais e antes e após tocar o paciente ou superfícies que estejam próximas a ele ${ }^{17}$.

Classe 5 - Conceito de infecção comunitária

Relacionada diretamente à classe 3 , a classe 5 possui 13 segmentos de texto, que representa 17,6\% do corpus. Contém os vocábulos (urinário, adquirir, internação, ambiente, intestinal, tuberculose), sendo a maioria dos acadêmicos do curso de medicina. Os estudantes foram perguntados e responderam qual o conceito de infecção comunitária que tinham aprendido no curso.

\footnotetext{
"uma infecção adquirida fora do ambiente hospitalar com menos de 48 horas de internação ou se internado adquirido no período de incubação da doença"

"é a infecção adquirida na comunidade causada por agentes infecciosos comuns nesse ambiente e que não sejam decorrentes dos procedimentos realizados em ambiente hospitalar"

"é uma infecção adquirida na comunidade não hospitalar adquirida de forma não relacionada a internação ou antes de 48 horas após admissão"
} 
"tétano, hepatite e aids"

Infecção comunitária é aquela que está estabelecida ou em incubação, antes da admissão do paciente nos serviços de saúde sem que haja registro de internação hospitalar anterior recente ${ }^{18}$.

Diferentemente da infecção comunitária a Infecção nosocomial ou infecção associada aos cuidados de saúde (IACS) são vistas em pacientes que estão sob cuidados médicos em alguma instituição de saúde, sendo que os sintomas surgiram não estavam presentes antes da admissão. Essas infecções podem ocorrer durante a prestação de cuidados para outras doenças ou mesmo após a alta. Além disso, também abrangem as infecções ocupacionais que ocorrem com a equipe médica. Está diretamente relacionada com dispositivos invasivos como cateteres ou ventiladores, além de infecções sanguíneas e de sítio cirúrgico ${ }^{19}$.

Classe 6 - Formas de contaminação de infecções comunitárias

Essa classe é associada às classes 4 e 2, agrupa 13 segmentos de texto, que representa 17,6\% do corpus. Com os vocábulos (interdisciplinar, informação, microbiologia, praticar, biossegurança, promoção, disciplina) e a maior parte dos estudantes do curso de odontologia e Idade entre 20 a 25 anos. Em suas falas, os alunos entrevistados, citaram algumas formas de contaminação de infecções comunitárias, que conheciam.

\footnotetext{
"compartilhamento de objetos entre parceiros e etc por um mesmo grupo de pessoas através que tenham candidíase, herpes bucal, úlceras, sapinho bucal”
}

As infecções podem se dar de forma endógena, quando alguém é infectado por um microrganismo que já estava presente na sua própria microbiota intestinal ou de forma exógena, quando o indivíduo adquiro um patógeno externo ao seu corpo. Além disso, podem existir formas diretas e indiretas de contaminação. A transmissão direta pode ser por meio de contato entre pessoas, pessoas e animais ou por gotículas infectadas que são expelidas por tosse, fala, espirro, etc. A transmissão indireta pode ser por aerossóis que ficam suspensos no ar por longos períodos; por veículos como objetos inanimados (recipientes, agulhas, curativos, maçaneta), água e comida contaminados, fezes (via fecaloral) e fluidos corporais; por vetores mecânicos que apenas carregam o patógeno (uma mosca pousa em fezes infectadas e depois nos alimentos), ou vetores biológicos que desempenham papel no desenvolvimento do patógeno (mosquito do gênero Anopheles na malária). Por fim, os microrganismos ganham acesso ao corpo por via muco-cutânea, respiratória, digestiva, geniturinárias transplacentária ou parenteral ${ }^{20}$. 


\section{CONCLUSÃO}

O profissional da saúde da Estratégia de Saúde da Família tem um papel importante na contenção das doenças infecciosas comunitárias, visto que estes têm o papel não só de cuidadores da saúde, mas também de educar e orientar a fim de promover a prevenção dessas contaminações.

A partir disso, compreende-se que esse papel só pode ser desempenhado através da adequada preparação do profissional, ainda durante sua formação acadêmica. Assim, o trabalho dispôs-se a analisar, por meio do método descritivo, o conhecimento dos estudantes de uma instituição privada dos cursos de medicina, enfermagem e odontologia.

A classe 1, acordando a avaliação do curso pelos estudantes sobre o controle de infecção comunitária na ESF, os vocábulos associados ao assunto (epidemiologia, processo, parasitologia, enfermagem, saúde, formação) tiveram maior frequencia nos alunos do gênero feminino, com idade 20-25 anos e cursando enfermagem. Nesse tópico evidenciou-se a necessidade de maior aprofundamento ao longo do curso. Além disso, ao ver-se que os acadêmicos tem maior valorização do conhecimento ciêntificodisciplicar ao invés da abordagem clínica, também é importante uma melhor preparação para preencher a lacuna entre a teoria e a prática profissional. A Classe 2, referente aos tipos de infecções comunitárias adquiridas na ESF, os acadêmicos de enfermagem, do gênero feminino e com idade entre 30 a 35 anos obtiveram maior destaque. Foram citados diversas patologias que atingiam os sistemas respiratório, urinário e cutâneo.

A Classe 3, apontando a interdisciplinaridade na grade curricular, teve maioria de alunos do curso de medicina, gênero masculino e com idade entre 20 a 25 anos. $\mathrm{O}$ assunto foi abordando dentro dos assuntos de infectologia, saúde de família, epidemiologia e entre outros. A Classe 4 sobre as formas de prevenção na ESF, teve maioria de estudantes do curso de odontologia, gênero masculino e idade entre 20 a 25 anos. Foi-se apontando a participação de palestras e outras atividades de caráter educativo sobre prevenção, higiene e cuidados para a população. Classe 5, evidenciando o conceito da infecção comunitária, teve maioria de acadêmicos do curso de medicina. Os estudantes apresentaram bom conhecimento sobre e exemplificaram. Classe 6, relativo às formas de contaminação, teve maior parte de respostas maioria de estudantes do curso de odontologia, gênero masculino e idade entre 20 a 25 anos.

Ainda que a infecção comunitária seja um assunto muito relevante para a saúde pública e os cursos abordem com certa frequência em diferentes disciplinas, o aprendizado dos estudantes ainda apresenta algumas lacunas que precisam ser fechadas tanto através do ensino teórico quanto a manutenção da prática clínica, o que pode ser realizado através das ações de extensão junto à comunidade. 


\section{REFERÊNCIAS}

1: Ministério da Saúde (BR). Portaria n. 2.436, de 21 de setembro de 2017 [Online]. 2017 [citado em 03 de julho de 2021. Disponível em: http://www.foa.unesp.br/home/pos/ppgops/portaria-n-2436.pdf.

2: Gusso G, Lopes JMC, Dias LC. Tratado de Medicina de Família e Comunidade: Princípios, Formação e Prática. 2nd ed. Porto Alegre: Artmed; 2019.

3: Sousa Gonçalves R, Carvalho MB, Fernandes TC, Veloso LSL, Santos LF, Sousa TR, Lopes ABA, Luz ITM. Educação em saúde como estratégia de prevenção e promoção da saúde de uma unidade básica de saúde. Brazilian Journal of health Review [Online]. 2020 [citado em 03 de julho de 2021];3(3):5811-5817. DOI 10.34119/bjhrv3n3-144. Disponível em: https://www.brazilianjournals.com/index.php/BJHR/article/view/11122/9319

4: Ministério da Saúde (BR), Secretaria de Gestão do Trabalho e da Educação na Saúde. Secretaria de Gestão do Trabalho e da Educação na Saúde: SGETS: políticas e ações. Brasília (DF); 2011.

5: Focaccia R, editor. Veronesi: tratado de infectologia. 5th rev. ed. São Paulo: Atheneu; 2015. Fatores de virulência microbiana; p. 3 - 9.

6: Falkenberg MB, Mendes TDPL, Moraes EPD, Sousa EMD. Educação em saúde e educação na saúde: conceitos e implicações para a saúde coletiva. Ciência \& Saúde Coletiva [Online]. 2014 [citado em 03 de julho de 2021];19(3):847-852. DOI 10.1590/1413-81232014193.01572013. Disponível em: https://www.scielo.br/j/csc/a/kCNFQy5zkw4k6ZT9C3VntDm/abstract/?lang=pt

7: Camargo BV, Justo AM. Tutorial para uso do software de análise textual IRAMUTEQ. Laboratório de Psicologia Social da Comunicação e Cognição [Online]. 2013 [citado em 12 de julho. 2021] Disponível em: https://www.iramuteq.org/documentation/fichiers/tutoriel-en-portugais

8: Oliveira DC, Gomes AMT, Marques SC. Análise estatística de dados na pesquisa das representações sociais: alguns princípios e uma aplicação ao campo da saúde. Casa do Psicólogo. Experiência e representação social - questões teóricas e metodológica. 2005

9: Aguiar AC, Ribeiro EC. Conceito e avaliação de habilidades e competência na educação médica: percepções atuais dos especialistas. Revista brasileira de educação médica. 2010;24: 371-378

10: Silva Filho, EB. Infecções Respiratórias de Importância Clínica: uma Revisão Sistemática. Revista FIMCA. 2017; 4(1):7-16

11: Miranda SIR, Cunha JN. Infecção Urinária Pediátrica: um estudo retrospectivo de 5 anos no Hospital Garcia de Orta. Monografia. Faculdade de Medicina da Universidade de Lisboa. 2016;

12: Haddad JM, Fernandes DA. Infecção do trato urinário. Federação Brasileira das Associações de Ginecologia e Obstetrícia (Febrasgo). 2018;63

13: De Paulo LF, Macedo AB, Frez FCV, De Souza SRG. Pielonefrite: Revisão Da Literatura. Arquivos Do Mudi. 2019;23(3):413-431 
14: Porto LAB, Lyon AC. Infecções Bacterianas da Pele. [Online].2017; [citado em 11 de julho. 2021] Disponível em: rluizporto.com.br/wp-content/uploads/2017/03/INFECÇÕES-BACTERIANAS-DAPELE-Capítulo-de-livro.pdf

15: Souza ACL. Colonização e infecção cutânea por Staphylococcus aureus resistente à meticilina associado à comunidade em crianças e adolescentes com afecções dermatológicas. [Online].2017; [citado em 11 de julho. 2021] Disponível em: https://app.uff.br/riuff/bitstream/1/7705/1/Dissertaçãofinal05.11.17.pdf

16: Sousa, ÁFL et al. Representações sociais da infecção comunitária por profissionais da atenção primária. Acta Paulista de Enfermagem. 2015; 28(1): 454-459.

17: Ministério da Saúde, Agência Nacional de Vigilância Sanitária, Fundação Oswaldo Cruz. Protocolo para a prática de higiene das mãos em serviços de saúde. Brasília: Anvisa. 2013; 1-3.

18: Henderson KL. Community-acquired, healthcare-associated and hospital-acquired bloodstream infection definitions in children: a systematic review demonstrating inconsistent criteria. Journalof Hospital Infection. 2013;85(2):94-105

19: Khan HA, Baig FK, Mehboob R. Riffat. Nosocomial infections: Epidemiology, prevention, control and surveillance. Asian Pacific Journal of Tropical Biomedicine. 2017;7(5):478-482

20: Médecins Sans Fronteires Academy For Healthcare. Introdução à prevenção e controle de infecção. [Online].2020; [citado em 05 de julho. 2021] Disponível em: https://coronavirus.msf.org.br/wpcontent/uploads/2020/06/Covid19_B1_PCI_Cadeia_de_Transmiss\%C3\%A3o_compressed.pdf 